\title{
Biosorption of copper using nopal fibres: moolooite formation and magnesium role in the reactive crystallization mechanism
}

\author{
Ara Carballo-Meilan • Elizabeth Hernández-Francisco • Gustavo Sosa-Loyde • \\ José Bonilla-Cruz $\cdot$ Paul Russell · Zulfiqur Ali · Alejandra García-García • \\ Alejandro Arizpe-Zapata • Francisco Longoria-Rodríguez • Tania E. Lara-Ceniceros • \\ Chun-Yang Yin
}

Received: 4 May 2020/Accepted: 10 September 2020/Published online: 12 October 2020

(C) The Author(s) 2020

\begin{abstract}
In this contribution, we present findings on biosorption of $\mathrm{Cu}$ (II) ions using novel alkali-treated nopal fibres. The biosorption data at equilibrium were fitted to several isotherm models and the biosorbent was characterized by XRD and SEM-EDX. The biosorption mechanism was investigated using a holistic approach of $\mathrm{pH}$ shifts, apparent colour variations and changes in the concentration of $\mathrm{Cu}(\mathrm{II})$ and dissolved hard ions (calcium and magnesium) in the $\mathrm{Cu}$ (II) solution. The correlation between the colour, XRD analysis, pH shifts and hard cations released from the biosorbent into the solution suggested the existence of two crystal formations, malachite and
\end{abstract}

A. Carballo-Meilan · P. Russell

School of Computing, Engineering and Digital

Technologies, Teesside University, Borough Road,

Middlesbrough TS1 3BA, UK

E. Hernández-Francisco · G. Sosa-Loyde ·

J. Bonilla-Cruz · T. E. Lara-Ceniceros ( $\varangle)$

Advanced Functional Materials and Nanotechnology

Group, Centro de Investigación en Materiales Avanzados

S. C. (CIMAV-Unidad Monterrey), Av. Alianza Norte

202, Autopista Monterrey-Aeropuerto Km 10, PIIT,

C.P. 66628 Apodaca, Nuevo León, México

e-mail: tania.lara@cimav.edu.mx

Z. Ali $(\square)$

Healthcare Innovation Centre, School of Health and Life

Sciences, Teesside University, Middlesbrough,

Tees Valley TS1 3BX, UK

e-mail: Z.Ali@tees.ac.uk moolooite, in what appears to be a microprecipitation mechanism via reactive crystallization. The role of magnesium during the transformation of malachite into moolooite during the copper binding mechanism is analysed. Magnesium cations were released into the solution during malachite growth but were taken up from the solution during the moolooite crystal growth phase. The shift of the molar ratio $\mathrm{Mg} / \mathrm{Ca}$ was located between the two inflexion points of the crystal growth transition. This specific location at the sorption isotherm was correlated with the colour evolution by a linear discriminant model confirming its association with the polymorphs. 


\section{Graphic abstract}

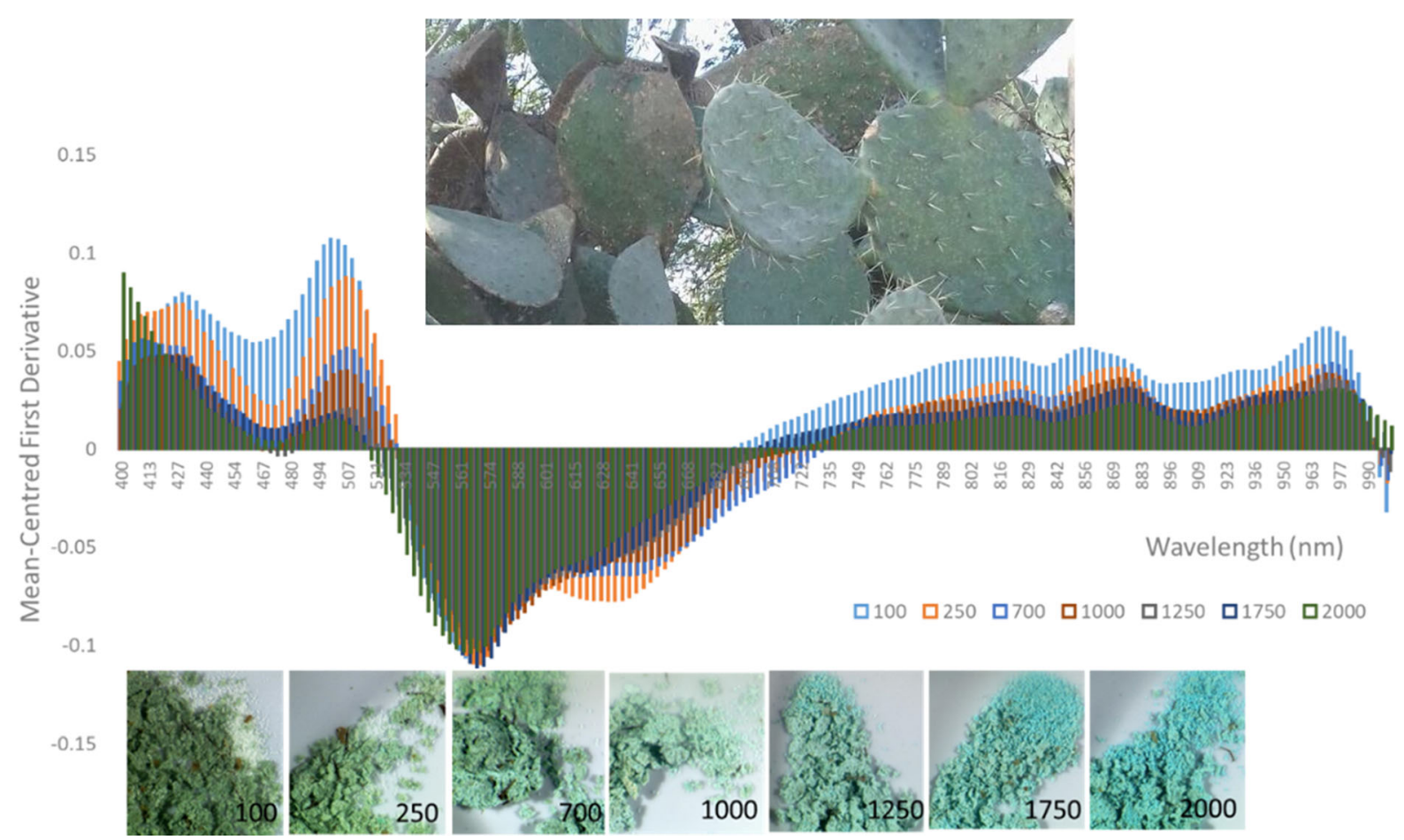

Keywords Biosorption - Microprecipitation · Crystallization $\cdot$ Moolooite $\cdot$ Cactus

\section{Introduction}

Opuntia Ficus-Indica, commonly referred to as nopal, is a type of cactus classified in the Opuntioideae genus in the Cactaceae family (Stevens 2017). A recent review (Nharingo and Moyo 2016), highlighted the numerous uses of this species, from pharmaceutical applications to water treatment. In the context of water treatment, biosorbents derived from nopal generally exhibit good adsorption capacities. This has been partially attributed to their multi-functional surface characteristics which incorporate phosphate, phenolic, hydroxyl, carboxylic, carbonyl, amide, amine and alkyl groups. Most studies describe the metal sorption mechanism as an ion exchange process whereby protons and alkali earth metal ions play a key role (Kotrba et al. 2011; Wahab et al. 2012; Escudero et al. 2017), and surface groups such as $\mathrm{C}-\mathrm{O}$ bonding sites are responsible for metal uptakes through ion-exchange (Bilal et al. 2013).

In general, the uptake of heavy metals by biosorbents has been associated to different phenomena including ion exchange, microprecipitation, chemisorption and physisorption (Robalds et al. 2016). Elucidating the metal sorption mechanism is a difficult task due to the complex nature of the biosorbent and the multiple roles that one single surface group can exhibit (Kotrba et al. 2011). For instance, carboxylic groups are observed to engage in both electrostatic attraction and complexation mechanisms. If an ion exchange process were responsible for the metal binding mechanism, the metal cations from the solution would generally be replaced with protons or other cations such as calcium or magnesium (the ones typically reported) in equivalent amounts, indicating that the charge released from and taken by the surface is balanced (Schneider et al. 2001; Kotrba et al. 2011). This is reflected in the following reaction: $S H+M^{+} \rightleftharpoons S M+H^{+}$, in which $S$ in the surface group holding the protons $H$ and $M$ denotes the metal cation. These alkaline metal cations are micronutrients associated with functional groups such as carboxylic 
groups of the biopolymer, located in the polysaccharides of hemicellulose and soluble compounds of the biosorbent (Velazquez Jimenez and Rangel Mendez 2014; Escudero et al. 2017). In the case of microprecipitation (also known as surface precipitation), the process involves the deposition of electrically neutral particles due to the limited solubility of the metal on the surface of the biosorbent (Kotrba et al. 2011). This could be produced by specific triggers in the vicinity of the biosorbent such as binding sites or physicochemical conditions, different to those in the bulk solution.

Although there are several reviews (Schneider et al. 2001; Robalds et al. 2016) and studies (Goldberg 1993; Kotrba et al. 2011) devoted to metal sorption mechanism via microprecipitation, they are still rather limited in the context of the ion exchange phenomena in biosorption research and this warrants further research. This forms an underlying motivation and basis to the research theme presented in the current study whereby alkali-treated nopal fibres are used as heavy metal biosorbent. It attempts to describe the relationship between colour changes observed in the biosorbent as complemented by spectroscopic analysis with equilibrium sorption data.

\section{Methodology}

\section{Biosorbent preparation}

Nopal biomass was obtained from the farm "Los Jacales" in Apodaca, Nuevo Leon, Mexico. Nopal cladodes aged (8-10 years old) were collected, the thorns removed with a knife, washed with distilled water and finally cut into small squares. Sodium hydroxide flakes $(\mathrm{NaOH}, \mathrm{ACS}$ grade) were purchased from Fermont. Raw nopal fibres (FNV) were treated in a solution of $5 \% \mathrm{NaOH}$ on a heating plate at $70{ }^{\circ} \mathrm{C}$ for $4 \mathrm{~h}$. The final FNV were filtered, washed with deionized water until neutral $\mathrm{pH}$ and dried in a vacuum oven. Alkaline treatment with $\mathrm{NaOH}$ is a process commonly referred as pulping as applied to wood and plant fibres with the aim of removing hemicellulosic material, mucilageneous polysaccharides, proteins, inorganic material and lignin. This basic hydrolysis process breaks down the linkages between the carbohydrates and lignin, and enhances the surface area of cellulosic fibres (Moon et al. 2011; Brinchi et al. 2013; Abdul Khalil et al. 2014).

\section{Adsorption}

In a typical adsorption experiment, the biosorbent $(5 \mathrm{~g} / \mathrm{L})$ was added into a copper nitrate solution $(25 \mathrm{ml})$ with initial $\mathrm{Cu}^{2+}$ concentration ranging from nil to $1,750 \mathrm{mg} / \mathrm{L}$. A Cu (II) stock solution $(2,000 \mathrm{mg} /$ L) was used for solution preparation. The solution was stirred at $80 \mathrm{rpm}$ and room temperature $\left(21 \pm 1^{\circ} \mathrm{C}\right)$ for $24 \mathrm{~h}$. Initial solution $\mathrm{pH}$ prior to the adsorption process was $4.4 \pm 0.2$. At the end of the contact period, the samples were centrifuged at 5,000 rpm for $10 \mathrm{~min}$. The supernatant was removed and recovered solid was oven-dried at $50{ }^{\circ} \mathrm{C}$ overnight and stored for further analysis in a micro-spectrophotometer. The supernatant was diluted in nitric acid $(0.2 \mathrm{M})$ and refrigerated. The concentration of $\mathrm{Cu}^{2+}$ was determined by atomic absorption spectroscopy (AAS). The equilibrium adsorption capacity was determined using the following equation:

$Q_{e}=\frac{\left(C_{0}-C_{e}\right) \cdot V}{W}$

where $Q_{e}$ is the adsorption capacity at equilibrium $(\mathrm{mg} / \mathrm{g}), W$ is the amount of biosorbent $(\mathrm{g}), C_{0}$ and $C_{e}$ are the initial and final $\mathrm{Cu}^{2+}$ concentrations, respectively (mg/L) and $V$ is the volume (L).

The equilibrium data were fitted to the Langmuir, Freundlich, Dubinin-Radushkevich and BET isotherm models. The Langmuir isotherm model (Langmuir 1916) is based on monolayer adsorption on active sites of the adsorbent and presented by the following equation:

$Q_{e}=\frac{Q_{m} b C_{e}}{1+b C_{e}}$

where $Q_{m}(\mathrm{mg} / \mathrm{g})$ and $b(\mathrm{~L} / \mathrm{mg})$ represent the monolayer adsorption capacity and Langmuir constant, respectively. The Freundlich equation (Freundlich 1906) is expressed as

$Q_{e}=K_{F} C_{e}^{1 / n}$

where $K_{F}$ and $n$ are constants. A linear plot of $\log Q_{\mathrm{e}}$ against $\log C_{\mathrm{e}}$ was employed to provide values of $K_{F}$ and $n$ from the intercept and slope of the plot, 
respectively. The linearized form of the DubininRadushkevich (D-R) model (Dubinin and Radushkevich 1947) can be expressed as follows:

$\ln Q_{\mathrm{e}}=\ln Q_{\mathrm{m}}-\beta \varepsilon^{2}$

where $Q_{\mathrm{m}}$ is the monolayer adsorption capacity (mg/ $\mathrm{g}), \beta$ is the constant linked to sorption energy $\left(\mathrm{mol}^{2} /\right.$ $\mathrm{kJ}^{2}$ ) and $\varepsilon$ is the Polanyi potential which is expressed as $R T \ln \left(1+1 / C_{\mathrm{e}}\right)$, where $R$ and $T$ are the gas constant $(\mathrm{kJ} / \mathrm{mol} . \mathrm{K})$ and temperature $(\mathrm{K})$, respectively. The plot of $\ln Q_{\mathrm{e}}$ versus $\varepsilon^{2}$ results in a straight curve. The slope of the D-R plot gives the $\beta$ constant value while $Q_{e}$ is determined from the intercept of the plot. The mean free energy of biosorption, $E$ can be determined by using the obtained $\beta$ value from $\mathrm{D}-\mathrm{R}$ isotherm via the following equation (Hobson 1969):

$E=1 /(2 \beta)^{0.5}$

$E$ can be further described as the energy needed to transfer one mole of sorbate to the surface from infinity (i.e. bulk fluidic environment). $E$ is used to establish the governing adsorption mechanism in which an $E$ value lesser than $8 \mathrm{~kJ} / \mathrm{mol}$ shows the predominance of physisorption mechanism while an $E$ value higher than $8 \mathrm{~kJ} / \mathrm{mol}$ shows that chemisorption is the main governing mechanism (Helfferich and Dranoff 1963).

Brunauer-Emmett-Teller (BET) isotherm describing multilayer adsorption for liquid phase on energetically homogenous solids can be expressed as (Ebadi et al. 2009):

$Q_{e}=\frac{Q_{m} K_{s} C_{e}\left[1-(m+1)\left(K_{L} C_{e}\right)^{m}+m\left(K_{L} C_{e}\right)^{m+1}\right]}{\left(1-K_{L} C_{e}\right)\left[1+\left(K_{s} / K_{L}-1\right) K_{L} C_{e}-\left(K_{s} / K_{L}\right)\left(K_{L} C_{e}\right)^{m+1}\right]}$

where $K_{s}(\mathrm{~L} / \mathrm{mg})$ is the equilibrium constant of adsorption for the first layer-it is a constant relating to the energy of interaction with the surface; $K_{L}$ (L/ $\mathrm{mg}$ ) is the equilibrium constant for upper layers; $Q_{m}$ $(\mathrm{mg} / \mathrm{g})$ is the monolayer saturation capacity and $m$ is the number of layers (when $m=1$ the BET isotherm reduces to Langmuir isotherm).

\section{Characterization}

Solution $\mathrm{pH}$ was measured before and after the adsorption experiments by using a Hanna Checker
HI-98103 pH meter. The concentration of $\mathrm{Cu}^{2+}$ was determined via a Thermo Scientific ${ }^{\mathrm{TM}}$ iCE $^{\mathrm{TM}} 3000$ Series AA spectrometer. A single element hollow cathode $\mathrm{Cu}$ lamp was used and the nebulizer flow rate was $3.5 \mathrm{~mL} \mathrm{~min}{ }^{-1}$. The concentrations of $\mathrm{Ca}^{2+}$ and $\mathrm{Mg}^{2+}$ released into the solution after equilibrium study, as well as in the control experiments, were measured by inductively coupled plasma mass spectrometry (ICP-MS) (Agilent 7500ce). X-ray diffractometry (XRD) analysis was conducted via an Eagle III $\mathrm{X}$-ray diffractometer using $\mathrm{CuK}_{\alpha}$ radiation, $\lambda=1.5406 \AA$, with voltage of $40 \mathrm{kV}$ and current of $20 \mathrm{~mA}$. Data was collected with a scan angle from 5 to $65^{\circ}$ and a scan speed of $0.02(1 \% \mathrm{~min})$. X-ray diffraction patterns of cellulose derivatives were recorded by XRD, EMPYREAN Panalytical onto a mono-oriented silicon sample holder in reflection mode using a Bragg-Brentano geometry, $5^{\circ} \leq 2 \leq 70^{\circ}$. Surface morphology of the biosorbent was analysed with a Hitachi S-3400 N SEM scanning electron microscope coupled with a EDX energy dispersive $\mathrm{x}$-ray spectroscopy detector operating at 1027 cps with a voltage of $30 \mathrm{kV}$ and a current of $140 \mathrm{~mA}$.

\section{Colour analysis}

In order to correlate the colour displayed by the biosorbent during adsorption experiments with chemical characteristics such as $\mathrm{pH}$ changes, binding copper concentrations and dissolved earth metal cations, the following procedure was established (Fig. 1). Colour analysis of the biosorbent was performed using a micro-spectrophotometer (video spectro comparator VSC5000). Each spectrum was recorded in reflectance mode $($ Lights $=$ Flood $100 \%$; longpass = Vis; $\quad$ bandpass $=$ Off; $\quad$ Magnification $=11.83$ ) for wavelength range from 400 to $1000 \mathrm{~nm}$. Statistical analysis was conducted using Microsoft Excel 2013, Minitab 17.1.0 and Tanagra 1.4.50 software. Prior to the statistical analysis, the overall data (physico-chemical variables generated using the $\mathrm{pH}$ meter, AAS and ICP-MS) were standardized using the following mathematical expression:

$z=\frac{x-\mu}{\sigma}$ 
where $z$ is the column-scaled data, $\mu$ is the overall mean and $\sigma$ is the standard deviation of the entire dataset. The autoscaled data possesses a zero mean and a standard deviation of one. In the case of data generated by micro spectrophotometry, every spectrum was centred and scaled (Standard Normal Variate, SNV) and then a second order polynomial first derivative with 15 window width was computed. SNV was conducted as a normalization algorithm on individual sample spectrum, similar to Eq. (7), to correct for multiplicative variations between spectra. In the filtering method, the first derivative was applied to eliminate baseline offset variations between samples and improve resolution.

After preprocessing, an optimization procedure was implemented to determine the right number of variables. This step reduced the dimensionality of the dataset and used exclusively the training set to ensure that the selection is unbiased. It applied a stepwise discriminant analysis method (STEPDISC, forward approach, $\mathrm{F}$ to enter $=3.84$ ). Subsequently, the predictors selected by the feature selection method were used as input variables with the same training set to build a classification model using a supervised learning algorithm (Linear Discriminant Analysis, LDA). Subsequently, the quality of the model was determined by using the test set. Validation included split train/test set using a random set of samples (iteratively) 100 times (train proportion was 0.7), cross-validation tenfold repeated 10 times and leave-one-out and bootstrap (100 replications repeated 10 times). Finally, an exploratory data analysis was conducted using Principal Component Analysis (PCA) to identify the patterns in the data. The numbers of samples $(n)$ and predictors $(p)$ involved in each step were as follows: feature selection $(n=6, p=186)$, LDA $(n=6, p=1)$, validation $(n=9, p=1)$ and PCA $(n=11, p=6)$.

\section{Results and discussion}

\section{Surface morphology and crystalinity}

The main elements found in the biosorbent based on the EDX results are oxygen, carbon, calcium and magnesium. In the XRD analysis, the peak at around $2 \theta=22^{\circ}$ would have been used to determine the degree of crystallinity of the cellulose fibres from Opuntia cactus skin (Ramezani Kakroodi et al. 2015). The absence of this peak in the XRD pattern (Fig. 2) would indicate the presence of amorphous components such as lignin and/or pectin and, hence, low crystallinity of the cellulose fibres present in the biosorbent. The following $\mathrm{Ca} / \mathrm{Mg}$ crystalline compounds were identified on Opuntia ficus-indica (Contreras-Padilla et al. 2015, 2016), Opuntia ellisiana (Monje and Baran 2005) and Opuntia basilaris (Ramezani Kakroodi et al. 2015) species using XRD and SEM analyses: calcium carbonate $\left[\mathrm{CaCO}_{3}\right]$, calcium-magnesium bicarbonate $\left[\mathrm{CaMg}\left(\mathrm{CO}_{3}\right)_{2}\right]$, magnesium oxide $[\mathrm{MgO}]$, monohydrated calcium oxalate $\left[\mathrm{Ca}\left(\mathrm{C}_{2} \mathrm{O}_{4}\right)^{r}\left(\mathrm{H}_{2} \mathrm{O}\right)\right]$ and dihydrated magnesium oxalate $\left[\mathrm{Mg}\left(\mathrm{C}_{2} \mathrm{O}_{4}\right)^{2} 2\left(\mathrm{H}_{2} \mathrm{O}\right)\right]$. According to ContrerasPadilla et al. (2015), the flower-like structures shown in Fig. 3a would correspond to calcium carbonate crystals. The presence of magnesium is also detected (Fig. 3b) which is possibly attributed to the presence of some Mg-containing crystals.

The narrow and sharp peaks around $2 \theta=$ $15.0^{\circ}, 24.5^{\circ}, 30.2^{\circ}, 36.1^{\circ}$ and $38.2^{\circ}$ are attributed to calcium oxalate crystals in nopal (Ramezani Kakroodi et al. 2015). The similarities between the present XRD and SEM-EDX results and those by Contreras-Padilla and co-researchers present a strong argument for the existence of different crystalline structures with several morphologies on the FNV-S surface. Despite the differences in the pre-treatment processes applied to the nopal samples, Fig. 2 shows remarkable resemblance to the diffractogram of nopal cladode powder (ibid) in relation to the position and relative intensities of the peaks. This comparative match probably indicates the presence of the several $\mathrm{Ca} / \mathrm{Mg}$ crystalline structures such as the presence of calcium carbonate and lower presence of calcium oxalate monohydrate. It was reported that cactus skins had high contents of calcium oxalate crystals (Ramezani Kakroodi et al. 2015) and that the synthesis method used to produce the biosorbent (alkaline conditions and washing of nopal cladodes) removes only a small portion of them (Malainine et al. 2003). In some molluscs, carboxylic acids or aliphatic alcohols act as templates for the nucleation and growth of the $\mathrm{CaCO}_{3}$ crystals (Goldberg 1993). Since this process is highly selective and nopal possesses many of these groups, an analogy of a similar formation of the calcite deposits on the FNV-S surface could be reasonably postulated. Furthermore, 
Fig. 1 Methodology of colour analysis

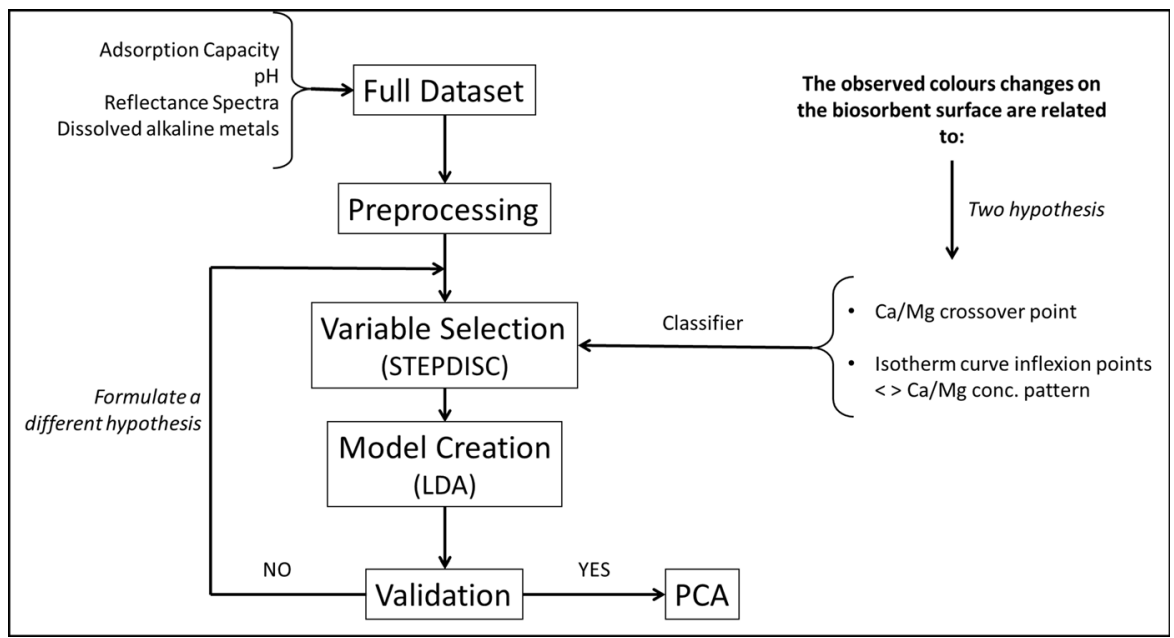

the biomineralization of calcite in many surfaces such as algae and biomass occurs primarily through heterogeneous nucleation (ibid).

\section{Adsorption isotherms}

Figure 4 shows biosorption isotherm which exhibits experimental data and calculated data points from the BET model. The obtained Langmuir, Freundlich, BET and Dubinin-Radushkevich parameters are listed in Table 1. The intrinsic shape or type of isotherm is dependent on the pore structure of the sorbent, the nature of the forces between the biosorbent surface and sorbate, concentration and energetic heterogeneity (Ruthven 1984). The $E$ value $(0.067 \mathrm{~kJ} / \mathrm{mol})$ as determined from the D-R equation was low and characteristic of a physical adsorption. This value of the free energy of adsorption seems too low to be consistent with the relatively good fit of the Langmuir model $\left(R^{2}=0.985\right)$, characteristic of a strong adsorption in this region (Schneider et al. 2001).

Reactive crystallization (also called precipitation) is a very unique and complex process (Myerson 2002). It occurs only if the solution is supersaturated, but unlike a typical crystallization process, high supersaturation conditions are produced by a chemical reaction (therefore supersaturation is determined by the concentration of the reactants). The reaction occurs promptly and there is a simultaneous occurrence of nucleation, crystal growth and secondary proceses (Ostwald ripening and agglomeration).
The rate of nucleation (and crystal growth) is governed by the degree of supersaturation, i.e., one of the most vital operational factors in the reactive crystallization of $\mathrm{CaCO}_{3}$ (Kitamura 2009). As soon as nucleation takes place in a supersaturated solution, the formed nuclei commence crystal growth. Crystals are thought to grow in a layer-by-layer fashion. The Kossel model divides an ideal crystal face into 3 surface structures (Myerson 2002): terraces (flat surfaces), steps (which separate terraces) and kink sites (incomplete regions on steps). The crystal growth process involves surface diffusion of solute, diffusion along the step to a kink and incorporation into the lattice at the kink site.

The kinetics of crystal growth have been correlated with adsorption isotherms and several mathematical expressions were developed (Davey 1976; Rousseau et al. 1976; Leung and Nancollas 1978; MielniczekBrzóska et al. 2000). In general, these studies describes the relationship between the adsorption of additives and impurities at kink sites and the observed crystal growth rates using both adsorption isotherms and independent crystal growth measurements. For instance, measurements of crystal growth rate were done during the adsorption of quinoline yellow dye on the (111) crystal face of potassium alum (Rousseau et al. 1976). The growth rates were measured at various dye concentrations and a plateau was observed at a certain concentration limit. The levelling off in growth rate was associated with the adsorption capacity of the face for the dye. 
Fig. 2 XRD pattern of pristine FNV-S

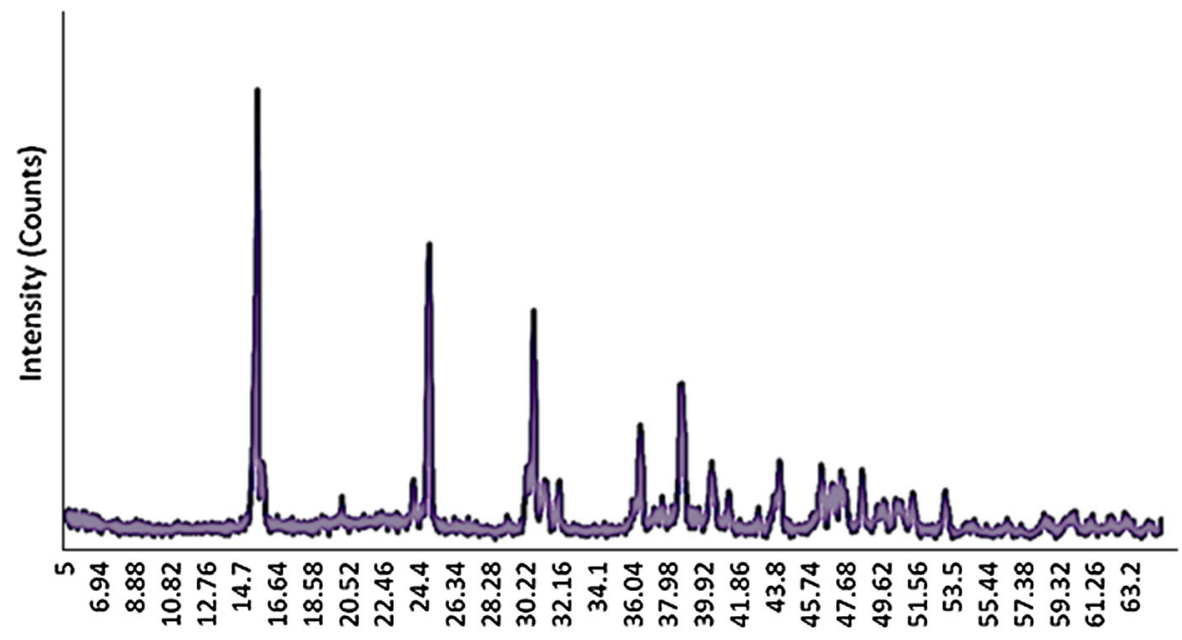

2-Theta $\left({ }^{\circ}\right)$
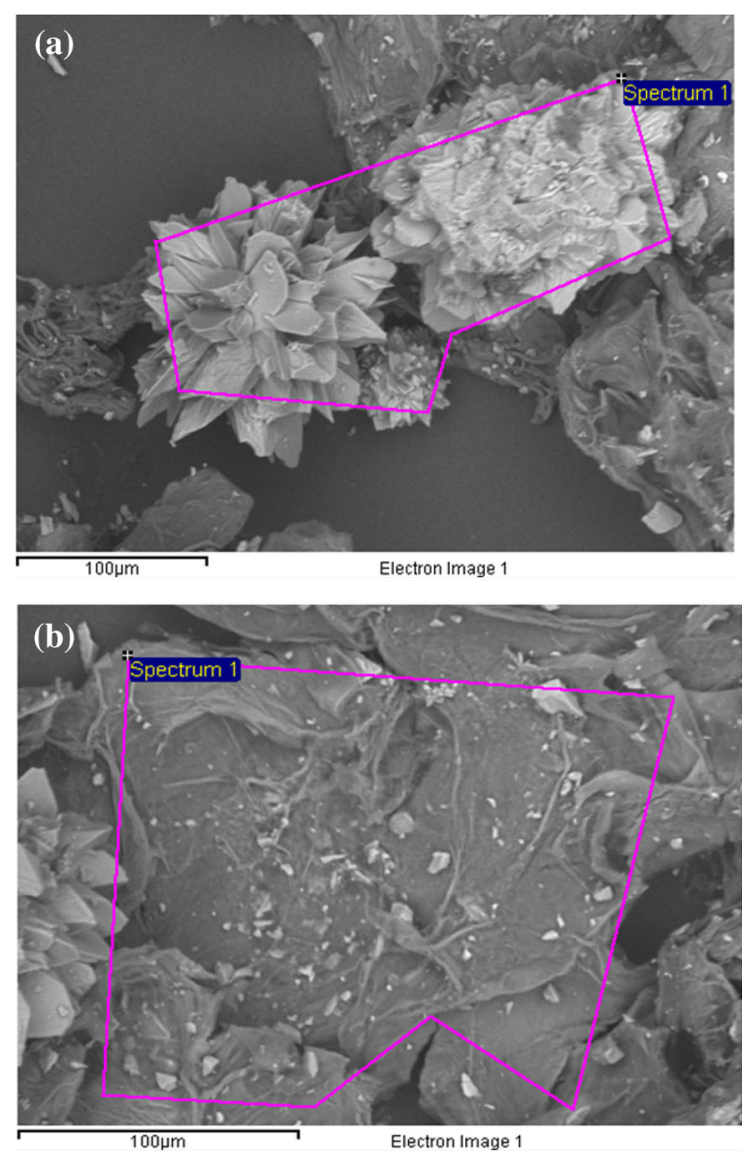

Fig. 3 Scanning electron micrographs of FNV-S biosorbent before adsorption experiment
The special case of the crystallization of barium sulphate, both in the presence and absence of methylenephosphonic acid (NTMP), is discussed due to the shape parallelism with our isotherm (Leung and Nancollas 1978). A strong adsorption of phosphonate ions through the formation of complexes with the barium ions at the crystal surface was modelled using the Langmuir isotherm. The adsorption took place at the crystal growth sites and the crystallization rate was proportional to the crystal area not covered by the adsorbate (in this case the additive inhibited the crystal growth). The Langmuir isotherm represented crystal growth. A linear relationship was found between the adsorption rate constants for adsorption and desorption at equilibrium with the rate constants for barium sulphate crystal growth. In the Langmuir isotherm, the first inflexion point occurred at the concentration at which the rate of the crystal growth reaction was completely inhibited. Their results indicated that adsorption took place at specific active growth sites on the crystal surface. The effect of the concentration of $\mathrm{Cu}$ (II) ions on the growth rates of ammonium oxalate monohydrate crystals was studied using a similar approach (Mielniczek-Brzóska et al. 2000). Like in the previous systems, the growth rate decreased with an increase in $\mathrm{Cu}(\mathrm{II})$ concentration.

We postulate that surface precipitation could occur in two steps: firstly a rapid growth on the surface plus a plateau, reached once the monolayer is completed on the biosurface (Region I, approximately drawn in Fig. 4). Within this stage, the metal is usually bound to 
specific sites in the biosorbent providing nucleation points. Then, the process is followed by a surface precipitation layer covering the adsorbed layer at a different crystal growth rate (corresponding to region II in Fig. 4). As the biosorbent reach saturation capacity the rate of growth decreases because all the active centres have already been occupied and no more layers can be formed.

Nonetheless, this microprecipitation model description is an ideal case. In reality there is no division between adsorption and precipitation (Goldberg 1993). Microprecipitation would occur at every point along the isotherm curve, even in the region were Langmuir seems to provide a good fit, but it would be the dominant "apparent" sorption mechanism only at high metal concentrations. An interesting description of the phenomena is provided by Goldberg (1993). The author describes two models that lead to surface precipitation, one initiated by adsorption and followed by precipitation, and another whereby heterogeneous nucleation would provide the means for the surface precipitation. In heterogeneous nucleation, three steps are usually involved: the adsorption of the ion onto the particle (one-dimensional), followed by surface nucleation (formation of a two-dimensional nucleous) and crystal growth (three-dimensional). Distinction between both cases requires a different type of study than the one done in the present report but analysis of the shape of the plot $\log Q_{e}$ versus $\log C_{e}$ has been used to distinguish between the two models. Based on Fig. 5, given the extension of the plateau, the constant changes in $\mathrm{pH}$ that follows and the S-shape, heterogeneous nucleation should not be completely ruled out until further evidences could be provided to elucidate the correct model. The inorganic microprecipitation of metals on biosorbents, initiated by heterogeneous nucleation has been previously described and typically displays this isotherm shape (Kotrba and Ruml 2010).

\section{$\mathrm{pH}$ variation}

The study on the solution $\mathrm{pH}$ variation was conducted for two stages: initial variations of $\mathrm{pH}$ in the blank were analysed and then compared with the $\mathrm{pH}$ changes observed in the adsorption process. In a typical blank sample experiment, FNV-S sorbent was agitated for $24 \mathrm{~h}$ in deionized water previously adjusted with $\mathrm{HNO}_{3}(0.2 \mathrm{M})$ at $\mathrm{pH} 4.6$, thus mirroring the batch adsorption isotherm study. In the blank sample, the change of $\mathrm{pH}$ was positive $(\Delta \mathrm{pH}=5.1 \pm 0.9)$, indicating a basic behaviour of the biosorbent in the solution. This $\mathrm{pH}$ increase was correlated with the protonation of basic groups on the biosorbent surface (Escudero et al. 2017). The $\mathrm{pH}$ shifts in the control sample were higher than the $\mathrm{pH}$ variations in $\mathrm{Cu}(\mathrm{II})$ solution observed in Fig. 6, where the biggest change measured was $\Delta \mathrm{pH}=0.6$. The dissolution of $\mathrm{CaCO}_{3}$ crystals in the biosorbent to $\mathrm{Ca}^{2+}$ and $\mathrm{CO}_{3}{ }^{2-}$ could be used to explain both observations and it will be discussed below. The $\mathrm{pH}$ of the initial $\mathrm{Cu}$ (II) concentrations (100 to $1750 \mathrm{ppm}$ ) is varied from 4.6 to 4.2 , with an average of $4.4 \pm 0.2$. Most of the variability in
Fig. 4 Biosorption isotherm for the present study

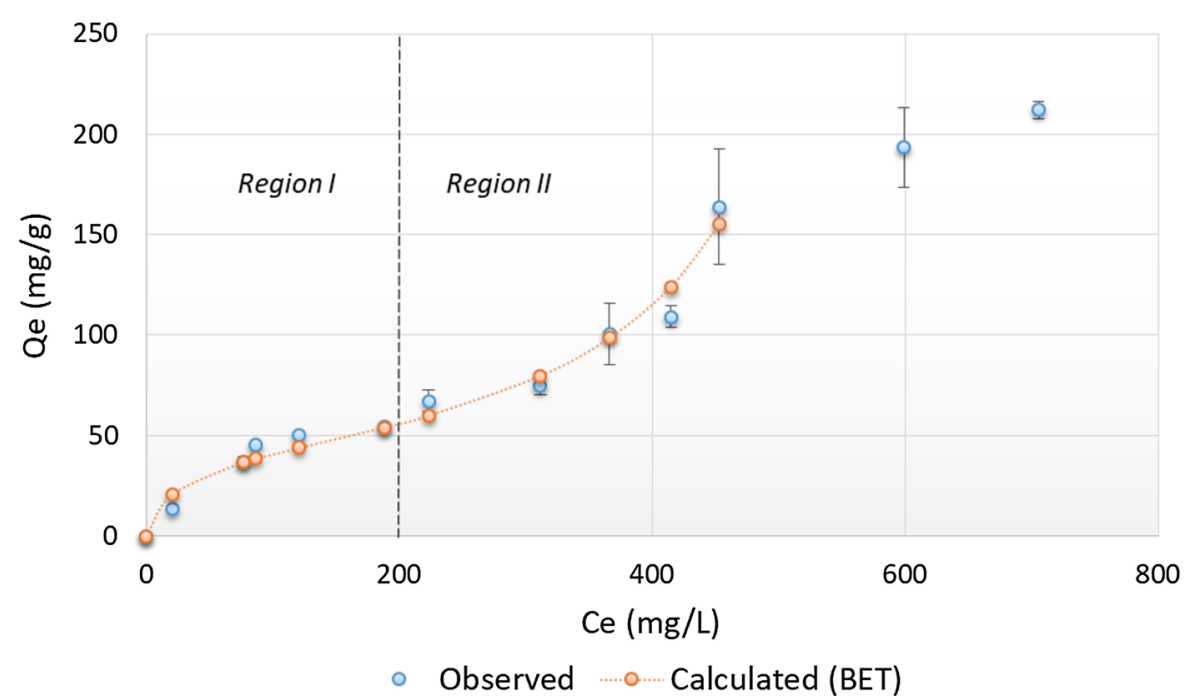


Table 1 Isotherm model parameters for biosorption of $\mathrm{Cu}$ (II) at $21^{\circ} \mathrm{C}$

\begin{tabular}{|c|c|c|c|c|c|c|c|}
\hline \multicolumn{4}{|c|}{ Langmuir parameters } & \multicolumn{4}{|c|}{ Freundlich parameters } \\
\hline \multirow{2}{*}{$\frac{Q_{\mathrm{m}}(\mathrm{mg} / \mathrm{g})}{82.06 \pm 10.46}$} & \multicolumn{2}{|c|}{$b(\mathrm{~L} / \mathrm{mg})$} & \multirow{2}{*}{$\frac{R^{2}}{0.985}$} & $K_{\mathrm{F}}$ & \multicolumn{2}{|l|}{$n$} & $R^{2}$ \\
\hline & $0.012 \pm$ & 0.003 & & $4.03 \pm 1.99$ & $1.95 \pm 0$. & & 0.958 \\
\hline \multicolumn{3}{|l|}{ D-R parameters } & \multicolumn{5}{|c|}{ BET parameters } \\
\hline$Q_{\mathrm{m}}(\mathrm{mg} / \mathrm{g})$ & $E(\mathrm{~kJ} / \mathrm{mol})$ & $R^{2}$ & $Q_{\mathrm{m}}(\mathrm{mg} / \mathrm{g})$ & $K_{s}(\mathrm{~L} / \mathrm{mg})$ & $K_{L}(\mathrm{~L} / \mathrm{mg})$ & $m$ & $R^{2}$ \\
\hline $50.08 \pm 3.33$ & 0.067 & 0.914 & $40.33 \pm 6.10$ & 0.046 & 0.0016 & 61 & 0.976 \\
\hline
\end{tabular}

the $\mathrm{pH}$ values, both before and after adsorption, corresponded to initial $\mathrm{Cu}(\mathrm{II})$ concentrations lower than $250 \mathrm{ppm}$. At equilibrium, an increment in $\mathrm{pH}$ took place in every sample and the higher the initial metal concentration was, the lower the changes in $\mathrm{pH}$ at equilibrium (Fig. 6). Similar results were found by Miretzky and co-workers (Miretzky et al. 2008) during the biosorption of $\mathrm{Pb}$ (II) metal cations onto the Opuntia Streptacantha biomass. The solution $\mathrm{pH}$ after equilibrium was always higher than at the beginning of the adsorption, including the control experiments. The results were attributed to the proton exchange with nopal cations in the carboxyl groups, mainly $\mathrm{Ca}^{2+}$ and $\mathrm{K}^{+}$. However, when the concentrations of $\mathrm{Pb}^{2+}, \mathrm{H}^{+}$ and $\mathrm{Ca}^{2+}$ after sorption were determined, there was an imbalance in the results that made it difficult to conclude if an exchange process really took place.

Figure 6 shows the amount of dissolved hard ions (mmol of $\mathrm{Ca}^{+2}$ and $\mathrm{Mg}^{+2}$ ) and the amount of sorbed copper ions $(\mathrm{mmol} \mathrm{Cu}(\mathrm{II}))$ as a function of the equilibrium copper concentration in solution during batch adsorption studies. The determination of these concentrations was done using ICP-MS analysis and the blank result was subtracted from the final readings. Changes in $\mathrm{pH}$ during the binding equilibrium experiments were also plotted in the secondary $y$-axis. Three distinctive regions are observed based on the data on the hard ions. At the beginning (initial low copper concentrations), both calcium and magnesium are dissolved into the solution. At this initial stage, the concentration of magnesium found in the solution is higher than the concentration of calcium and the solution gets more acidic as the concentration of copper increases. However, once it enters the second region, the changes in $\mathrm{pH}$ are constant and the moles in solution for calcium and magnesium are almost equal, while the amount of $\mathrm{Cu}$ (II) adsorbed keeps rising steadily. Once the concentration of copper starts to increase significantly, a change in the value of these variables marks the beginning of region III. In this last stage, the amount of calcium dissolved into the solution rises and then stabilizes, while the amount of magnesium decreases and then stabilizes. Overall, there is more calcium than magnesium being released into the solution from the biomass, as opposite of what happened in Region I.

It is a well-known fact that the biosorption mechanism can be explained by bioprecipitation and biocrystallization processes if calcium carbonate was present in the biomass (Vijayaraghavan et al. 2010, 2011; Du et al. 2011). Two stages are proposed: firstly, the $\mathrm{CaCO}_{3}$ is dissolved to $\mathrm{Ca}^{2+}$ and $\mathrm{CO}_{3}{ }^{2-}$; then the carbonate ion reacts with the metal $(\mathrm{M})$ to form the precipitate with the general equation $\mathrm{MCO}_{3}$, as the whole process is $\mathrm{pH}$ dependent. This precipitation process is typically accompanied by an increase in $\mathrm{pH}$ associated with the dissociation of carbonate species from the calcium carbonate. Subsequently, the insoluble metal carbonate formed is sorbed by the polymers of the studied biomass. At low metal concentrations, the binding between the metal and the calcite is through ion exchange and complexation but at high metal concentrations dissolution-precipitation prevails.

At a working $\mathrm{pH}$ between 3 and 5 and in the presence of $\mathrm{Cu}^{2+}$ cations, part of the $\mathrm{CO}_{3}{ }^{2-}$ would be complexed with the heavy metal as $\mathrm{CuCO}_{3}(\mathrm{~s})$, thus avoiding its release into the solution. This would still increase the solution $\mathrm{pH}$ with respect to control experiments (no biosorbent) but not as much as in blank experiments (no copper). Similar results were obtained for the removal of $\mathrm{Pb}$ (II), $\mathrm{Cd}(\mathrm{II})$ and $\mathrm{Zn}$ (II) cations by different types of mollusc shells (Lee et al. 1997; Kim and Park 2001; Du et al. 2011), a biosorbent with a high calcium carbonate content. These studies showed that the removal of metal 


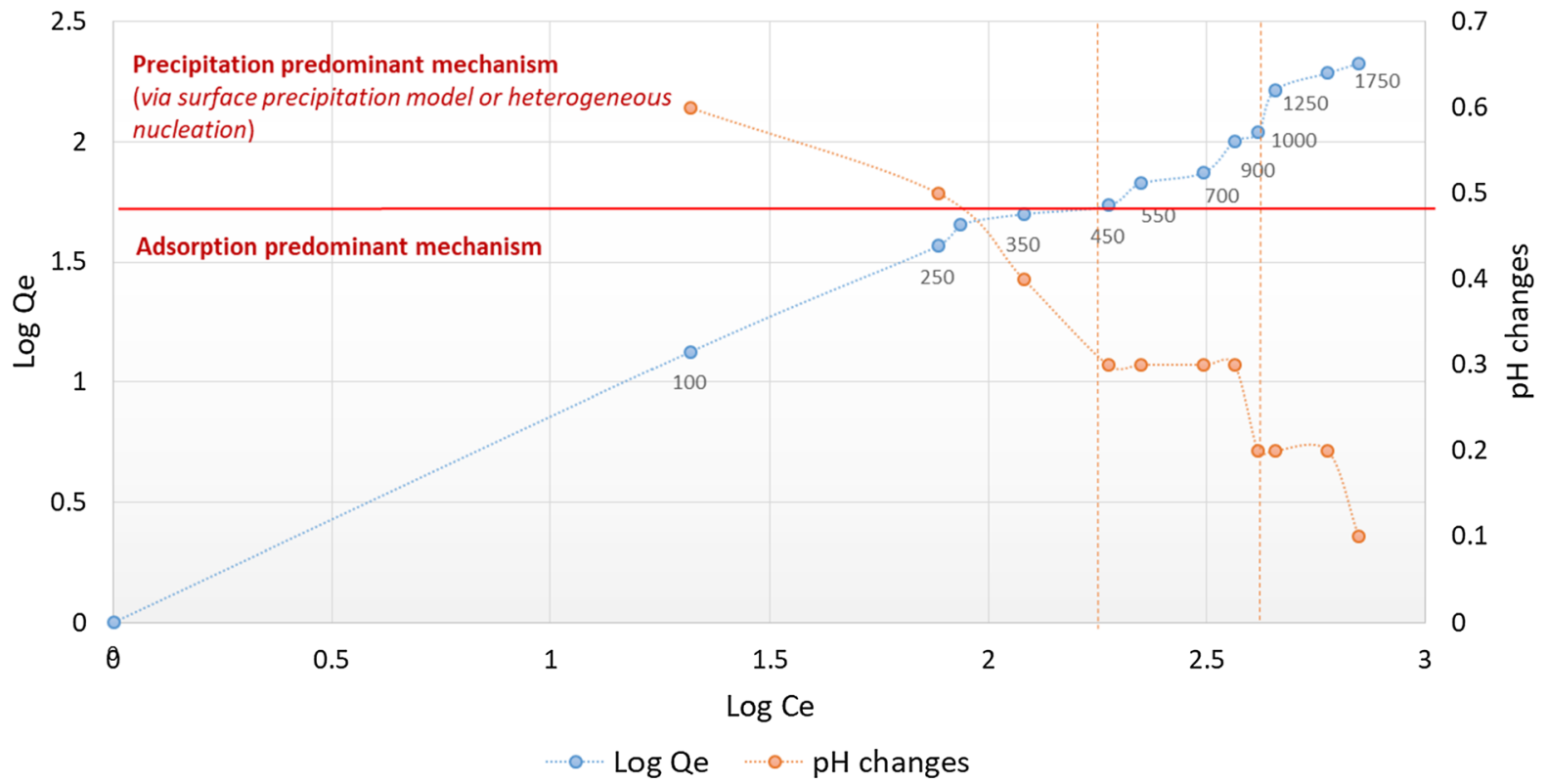

Fig. 5 Sorption isotherm scheme as described by Goldberg (1993)

cations took place mainly by the dissolution of $\mathrm{CaCO}_{3}$ followed by the precipitation leading to crystal growth of hydrocerussite $\left[\mathrm{Pb}_{3}\left(\mathrm{CO}_{3}\right)_{2}(\mathrm{OH})_{2(\mathrm{~s})}\right]$, cerussite $\left[\mathrm{PbCO}_{3(\mathrm{~s})}\right]$, hydrozincite $\left[\mathrm{Zn}_{5}\left(\mathrm{CO}_{3}\right)_{2}(\mathrm{OH})_{6(\mathrm{~s})}\right]$, and otavite $\left[\mathrm{CdCO}_{3(\mathrm{~s})}\right]$ formed both on the surface of the biosorbent and in the solution.

Interestingly, it has also been mentioned that calcium is found acting as bridges between the carboxyl groups of cellulose, hemicellulose, pectin and lignin polymers of the biomass (Bernardo et al. 2009) which would render them exchangeable with the metal cations (Wahab et al. 2012). Furthermore, in many metal biosorption studies with Opuntia species (Barrera et al. 2006; Miretzky et al. 2008; Barka et al. 2013; Prodromou and Pashalidis 2013; FernándezLópez et al. 2014; Beltrán-Hernández et al. 2015), only a sorbate-sorbent electrostatic interaction was described in most of the cases using pH, FTIR, and SEM analysis as main characterization techniques. Nonetheless, the presence or absence of calcite or other crystalline structures on the Opuntia biomass was not mentioned.

In Region I, the dissolution of magnesium was higher than the release of calcium ions. Previous studies indicated that the presence of $\mathrm{Mg}^{2+}$ ions in solution appeared to retard the dissolution calcite (Morse et al. 2007; Xu and Higgins 2011). This would explain the lesser dissolution of calcium carbonate in
Region I, where the amount of magnesium in solution was higher. As the magnesium is taken from the solution in Region III, this would propel the release of calcium. As indicated previously, when the isotherm reaches point $C$ (Fig. 6), an increase in $\mathrm{Ca}$ ion concentration is observed, while at the same time $\mathrm{Mg}$ ion concentration decreases. This can be attributed to dissolution of $\mathrm{Ca}$ crystals and at the same time nucleation of $\mathrm{Mg}$ crystal. The dissolution of $\mathrm{Ca}$ crystals would provide the necessary supersaturation for the formation of $\mathrm{Mg}$ crystals.

\section{Colour study}

In general, transition metals form coloured compounds depending on several factors such as the charge of the metal ion and the type of groups attached to the metal. The apparent colour shown by the pristine biosorbent is golden but once biosorption occurs, the biomass changes colour, shifting from green to turquoise as the concentration of copper increases (Fig. 7). This could be attributed to two different crystal formations on the biomass, namely, green malachite $\left[\mathrm{Cu}_{2}\left(\mathrm{CO}_{3}\right)(\mathrm{OH})_{2(\mathrm{~s})}\right]$ and the other turquoise moolooite $\left[\mathrm{CuC}_{2} \mathrm{O}_{4}{ }^{n} n \mathrm{H}_{2} \mathrm{O}_{(\mathrm{s})}(n<1)\right]$. Moolooite is a copper oxalate mineral associated with malachite and with a structure poorly understood (Demartin et al. 2018). The presence of malachite and moolooite 


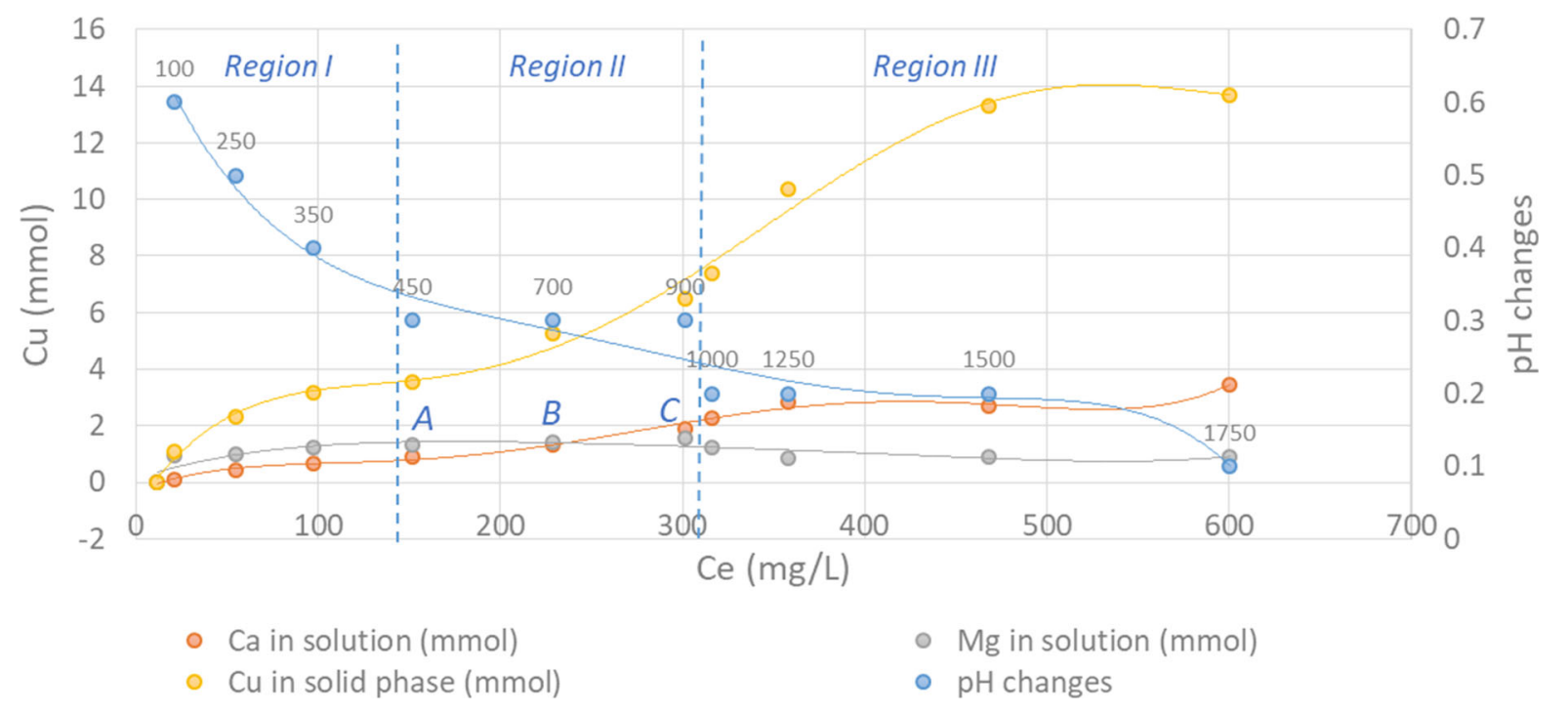

Fig. 6 Earth metal concentration trends for the adsorption process as a function of initial concentration measured by ICP-MS analysis. Points A, B and C were used to build the classifier in the colour study

crystals were confirmed by XRD analysis and the main findings are explained in the next section. Saturated samples at low coverage displayed two different zones, the green bulk material and some lighter grains that turn blue as the concentration of copper increases. Spectral data at both locations were considered and incorporated to the model. Pre-processed reflectance spectra were recorded on the dried solid fibres (Fig. 8) and was statistically analysed to correlate the colour changes to chemical features. The spectrum in the 400-1000 nm wavelength range was used. As Fig. 8 shows, the signal seems sensitive to the changes in copper concentration at different wavelengths.

There were two markers, 427 and $558 \mathrm{~nm}$ wavelengths, able to discriminate between groups (using both two- and three-class classifiers). The wavelengths of light reflected by the surface of the biosorbent and selected by the STEPDISC method corresponded to the colours blue $(427 \mathrm{~nm})$ and green $(558 \mathrm{~nm})$. The next step after selecting the important predictors was to conduct linear discriminant analysis. The most optimum model for classification was obtained when the crossover point B from Fig. 6 was used to build the discrete class attribute. The continuous attribute was the discriminator wavelength $427 \mathrm{~nm}$, filtered through the STEPDISC previous method. Table 2 shows the classification functions with their statistical evaluation as well as their validation analysis.
The significance of the difference was checked using a multivariate analysis of variance (MANOVA) and two transformations of its lambda, Bartlett and Rao transformations. A significant difference was found when the Wilks' lambda statistic (0.021) was computed. The closer it is to zero, the better the separation is (Rakotomalala 2005). According to Rao's transformation (for small sample sizes, $p<0.01$ ), the measured difference on the observations did not seem due to chance (Rao-F $(1,4)=186.9074, p$ value 0.0002). Error rate estimation included $\mathrm{CV}$, bootstrap, LOO and independent test sets. The model is stable and shows low classification error. The good separation observed in the boxplot of Fig. 9 also confirms the differences between the two groups based on the single wavelength and indicates the relationship between changes in calcium and magnesium contents in solution and the colour changes observed. A model including the $558 \mathrm{~nm}$ wavelength as additional predictor is also possible. However, it does not seem to give better results than the one explained above. This second model showed bigger separation between groups (Wilks' lambda statistic of 0.0049) but higher classification error in the test set (0.0533). The wavelengths subset from the STEPDISC procedure and the chemical features previously described were used as input in an exploratory data analysis to visualize the relationship between the samples and the predictors. 
Most of the data was modelled using just the first two principal components; this corresponded to a cumulative percentage eigenvalue of $89.59 \%$ (59.88\% and $29.70 \%$ for PC1 and PC2, respectively).

The scores extracted from PCA were used for interpreting the samples and loadings to determine which variables were related to the samples. The scores and the loadings were overlaid in what was called a biplot (Fig. 10). Three distinctive groups can be observed in the data. From this analysis, it can be concluded that the dissolved magnesium is more positively associated with the wavelength $558 \mathrm{~nm}$ and Region II (Fig. 6). On the other hand, the $\mathrm{pH}$ variations, wavelength $427 \mathrm{~nm}$, dissolved calcium and the adsorption capacity are the variables responsible for the formation of the first principal component and related to Regions I and III (Fig. 6). In this case, the adsorption capacity is positively associated with the amount of calcium released into the solution and both have an inverse relationship with the changes in $\mathrm{pH}$ and the wavelength $427 \mathrm{~nm}$. The colour gradation as a function of $\mathrm{Cu}$ (II) initial concentration is illustrated in Fig. 11.

XRD study and mechanism of crystal formation

This section compares the XRD spectra of saturated biosorbent samples after the contact period of $24 \mathrm{~h}$ as a function of the initial copper concentration (Fig. 12). Three types of crystalline structures were identified by XRD analysis: calcium oxalate $\left(\mathrm{CaC}_{2} \mathrm{O}_{4}{ }^{\circ} \mathrm{H}_{2} \mathrm{O}\right)$ at $2 \theta=15.0^{\circ}, 24.5^{\circ}, 30.2^{\circ}, 36.1^{\circ}$ and $38.2^{\circ}$, malachite $\left(\mathrm{Cu}_{2} \mathrm{CO}_{3}(\mathrm{OH})_{2}\right)$ at $2 \theta=14.8^{\circ}, 17.57^{\circ}, 24.1^{\circ}, 31.32^{\circ}$ and moolooite $\left(\mathrm{CuC}_{2} \mathrm{O}_{4}{ }^{\circ} n \mathrm{H}_{2} \mathrm{O}\right)$ at $2 \theta=22.9^{\circ}$ and $36.2^{\circ}$. While higher concentrations of copper in the sorption experiment led to an increase of copper oxalate in the final precipitate, the amount of calcium oxalate and malachite showed a decrease as the initial $\mathrm{Cu}$ (II) concentration increased. The confirmation of the presence of these two crystals, malachite and moolooite, in the exhausted solid suggests the hypothesis whereby malachite would transform into moolooite by a case of reactive crystallization and the magnesium ion would play the role of stabilizing the final copper oxalate precipitate. Two important examples of this transformation can found in the literature.

Green copper pigments, such as malachite, are known to suffer chromatic alterations associated with oxalate formation in art works (Castro et al. 2008; Rosado et al. 2013). The biodegradation of malachite to copper oxalates like moolooite through copper intermediates was observed in these paintings (Castro et al. 2008). The authors postulated a similar mechanism to the one reported in the present study. In their system, the action of microorganisms excreting oxalic acid on the green pigments was responsible for the

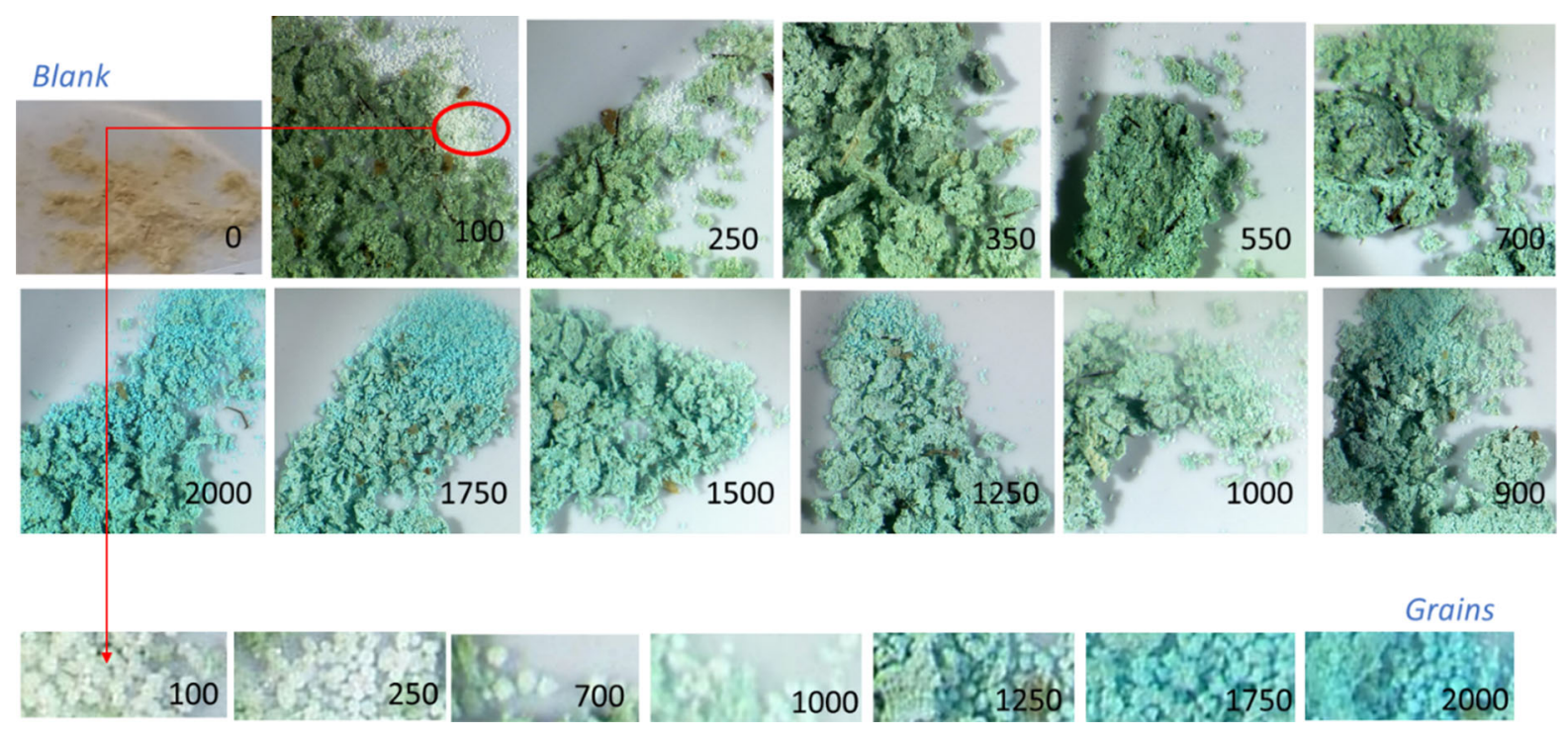

Fig. 7 VSC images of the biosorbent at different stages of the isotherm curve. The number indicates the corresponding initial copper concentration $(\mathrm{mg} / \mathrm{L})$ used in each experiment 


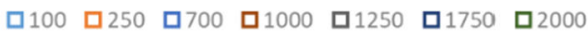

0.15

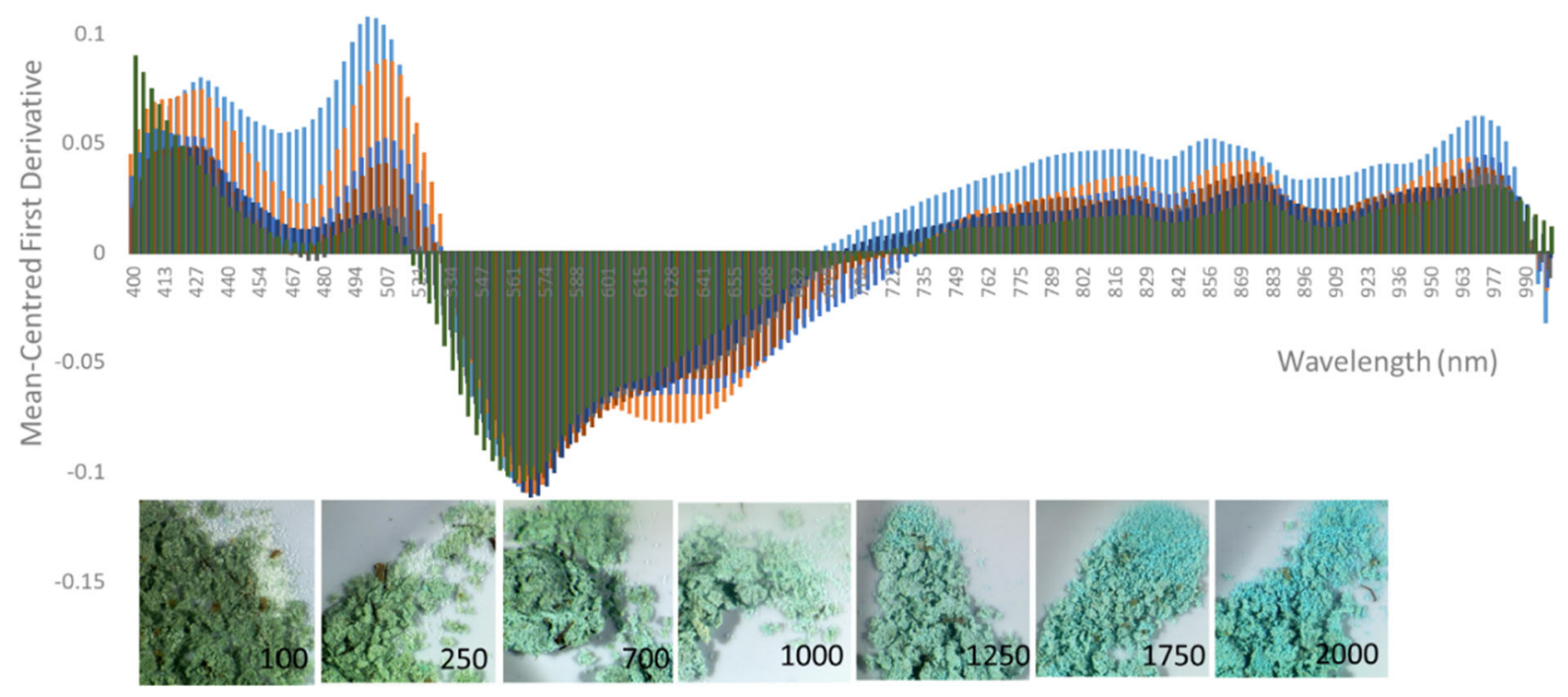

Fig. 8 Pre-processed UV-Vis spectra and corresponding microscopic images of biosorbent particles at equilibrium conditions. The numbering represents the initial $\mathrm{Cu}(\mathrm{II})$

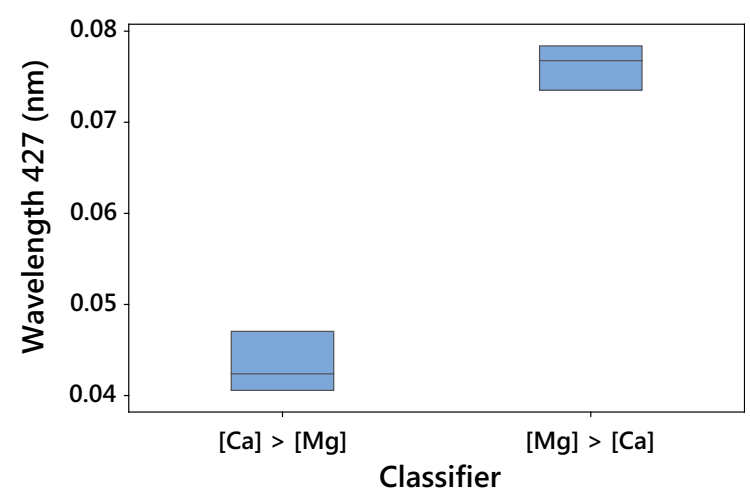

Fig. 9 Boxplot of the differences between calcium and magnesium dissolved in the solution based on the different intensities measured at $427 \mathrm{~nm}$

transformation of malachite into moolooite whenever the system contained enough oxalic acid. The oxalic acid attacked the calcite $\left(\mathrm{CaCO}_{3}\right)$ of the cellulose support to produce calcium oxalate: $\mathrm{H}_{2} \mathrm{C}_{2} \mathrm{O}_{4}+$ $\mathrm{CaCO}_{3}+\mathrm{H}_{2} \mathrm{O} \rightarrow \mathrm{CaC}_{2} \mathrm{O}_{4} \cdot 2 \mathrm{H}_{2} \mathrm{O}+\mathrm{CO}_{2}(\mathrm{~g})$ and suitable moist conditions produced an acidic environment to initiate the reaction. The evolution of $\mathrm{pH}$ represented as a function of the concentration of oxalic acid was also illustrated and resembles the one reported in Fig. 6. Based on their findings, the $\mathrm{pH}$ concentration (mg/L) used per experiment. Intermediate concentrations were omitted to improve visual clarity

dropped during the decay of malachite (Fig. 6Region I) and then remained constant during the formation of copper intermediates (Fig. 6-Region II) but when moolooite, the final product of the degradation, was formed a significant $\mathrm{pH}$ drop was observed (Fig. 6-Region III). The chemical composition of their system included the presence of calcium oxalate dihydrate (weddellite, $\mathrm{CaC}_{2} \mathrm{O}_{4} \cdot 2 \mathrm{H}_{2} \mathrm{O}$ ). In our system calcium and magnesium oxalate are part of the mineral composition of the FNV biomaterial together with amorphous calcite (Monje and Baran 2005). However, the hydration state of calcium oxalate differs. Only monohydrate (whewellite) calcium oxalate is found in Opuntioideae species (Monje and Baran 2005). Apparently, these differences in the polymorphism of the mineral oxalates do not seem to affect the mechanism.

The transformation of malachite to moolooite is likely to be involved as well in renal stone investigations. Kidney stones are hard, rock-like crystals with variable crystal habit and chemical composition (Selvaraju et al. 2013). However, some generalizations can be made about them (Khan et al. 1996; Singh and Rai 2014): (a) calcium is the predominant element in most human urinary stones combined with oxalate 
Table 2 Classification functions for dissolved hard metals concentration pattern

Class One corresponds to samples with higher magnesium content in solution and Class Two is representative of samples with higher calcium content

\begin{tabular}{|c|c|c|c|c|c|c|}
\hline \multirow[t]{2}{*}{ Attribute } & \multicolumn{2}{|c|}{ Classification functions } & \multicolumn{4}{|c|}{ Statistical evaluation } \\
\hline & $\begin{array}{l}\text { Class one } \\
{[\mathrm{Mg}]>[\mathrm{Ca}]}\end{array}$ & $\begin{array}{l}\text { Class two } \\
{[\mathrm{Ca}]>[\mathrm{Mg}]}\end{array}$ & Wilks L. & Partial L. & $\mathrm{F}(1,4)$ & $p$ value \\
\hline 427 & 8770.901 & 4984.088 & 1 & 0.0210 & 186.9074 & 0.0002 \\
\hline Constant & -334.924 & -108.620 & & & & \\
\hline \multicolumn{7}{|c|}{ Validation analysis } \\
\hline $\mathrm{CV}$ & \multicolumn{2}{|c|}{ Bootstrap } & \multicolumn{2}{|r|}{ LOO } & \multicolumn{2}{|r|}{ Train-test } \\
\hline 0 & \multicolumn{2}{|c|}{0.0115} & \multicolumn{2}{|r|}{0} & \multicolumn{2}{|r|}{0} \\
\hline
\end{tabular}

and phosphate in the form of calcium oxalate, calcium phosphate and calcium carbonate; (b) Heavy metals may take part in the initiation of stone crystallization and copper was seen to play an important role in kidney stone formation; (c) the amount of copper stored in the stones is significantly higher if compared with other trace elements.

The biomineralization mechanism of urinary stones is still under debate (Selvaraju et al. 2013; Singh and Rai 2014) and in particular, the role of magnesium in kidney stone formation remains unsolved due to contradictory scientific results (Ryall 2011). The emphasis of current investigations is to explore the role that major and trace elements play in the mechanism of formation of these stones. In the case of magnesium, its role in kidney stone formation might depend on the initial composition of the urine.
In particular, in urinary stones where calcium oxalate is the predominant component (typical composition in Asiatic patients as opposed to Western patients that also contains calcium phosphate), Fourier TransformRaman spectroscopy analysis revealed the presence of calcium oxalate, moolooite and glushinkite (magnesium oxalate) as part of the stone chemical composition (Selvaraju et al. 2013). By analogy with our proposed mechanism (Fig. 13), if the magnesium was taken from the urine during the crystallization process to stabilize moolooite, this would explain why Asiatic stone patients with higher copper levels than healthy controls have magnesium levels in their urine lower than the controls (Atakan et al. 2007; Ryall 2011), an affect that still puzzles researchers.
Fig. 10 Biplot (loading vectors for first two principal components) showing the correlation between the variables and the principal components

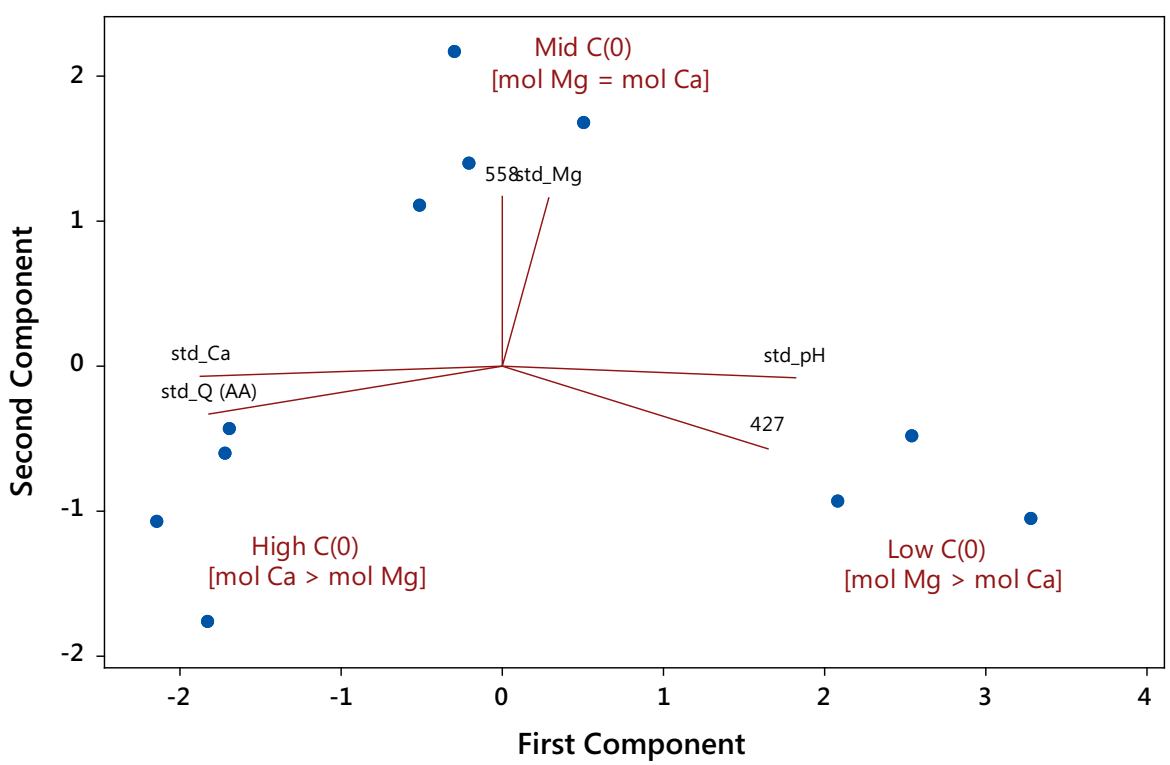


Fig. 11 Colour gradation as a function of $\mathrm{Cu}$ (II) initial concentration $(\mathrm{mg} / \mathrm{L})$
Region I

- Adsorption Dominant

- $\mathrm{pH}$ decreases

- $(\mathrm{mmol} \mathrm{Mg})_{\mathrm{sol}}>(\mathrm{mmol} \mathrm{Ca})_{\mathrm{sol}}$

- Observed Colour: Green

- Positively Correlated $\lambda$ : $427 \mathrm{~nm}$

Malachite Crystals $\mathrm{Cu}_{2}\left(\mathrm{CO}_{3}\right)(\mathrm{OH})_{2}$

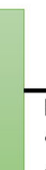

Region II

- $\mathrm{pH}$ is constant

- $(\mathrm{mmol} \mathrm{Mg})_{\text {sol }}=(\mathrm{mmol} \mathrm{Ca})_{\text {sol }}$

- Observed Colour: Green-Blue

- Positively Correlated $\lambda: 558 \mathrm{~nm}$
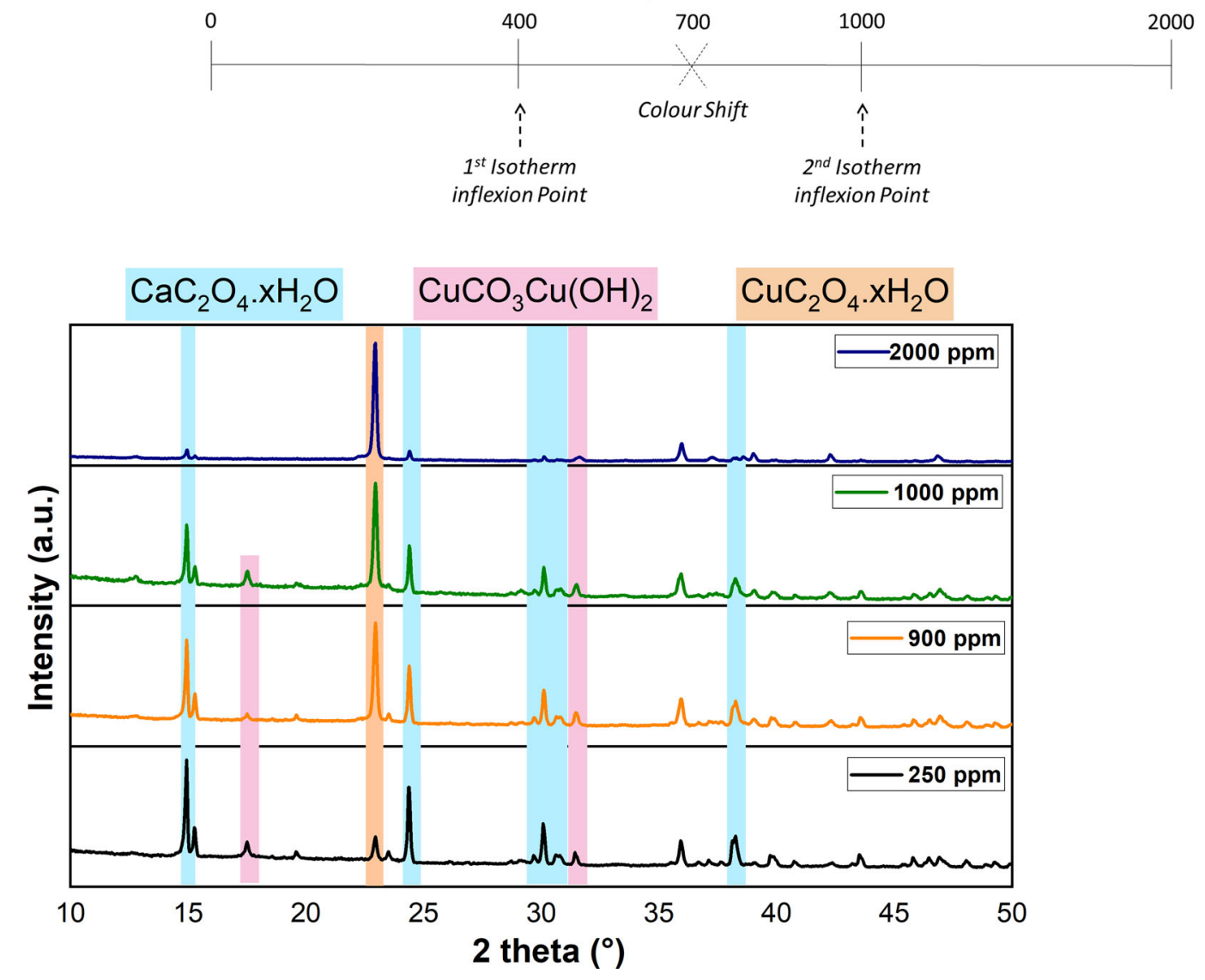

Fig. $12 \mathrm{XRD}$ as a function of the $\mathrm{Cu}$ (II) initial concentration (mg/L)

\section{Conclusions}

A novel biosorbent has been successfully synthesized via alkali treatment of nopal fibres and used as heavy metal biosorbent. The relationship between colour changes observed in the biosorbent as complemented by spectroscopic analysis with equilibrium sorption data have been described. Several crystalline structures containing $\mathrm{Ca}$ and $\mathrm{Mg}$ were identified on the surface of the biosorbent, including an important presence of calcium carbonate crystals. Overall, these findings contribute to the understanding of calcium carbonate dissolution mechanism from a biomass surface as a function of the amount of magnesium being released and the concentration of copper ion present in the solution. As a result of the microprecipitation process, two types of precipitate formation were observed. At low copper concentrations, malachite crystals were dominant on the cactus biomass but as the concentration of copper increased, moolooite 


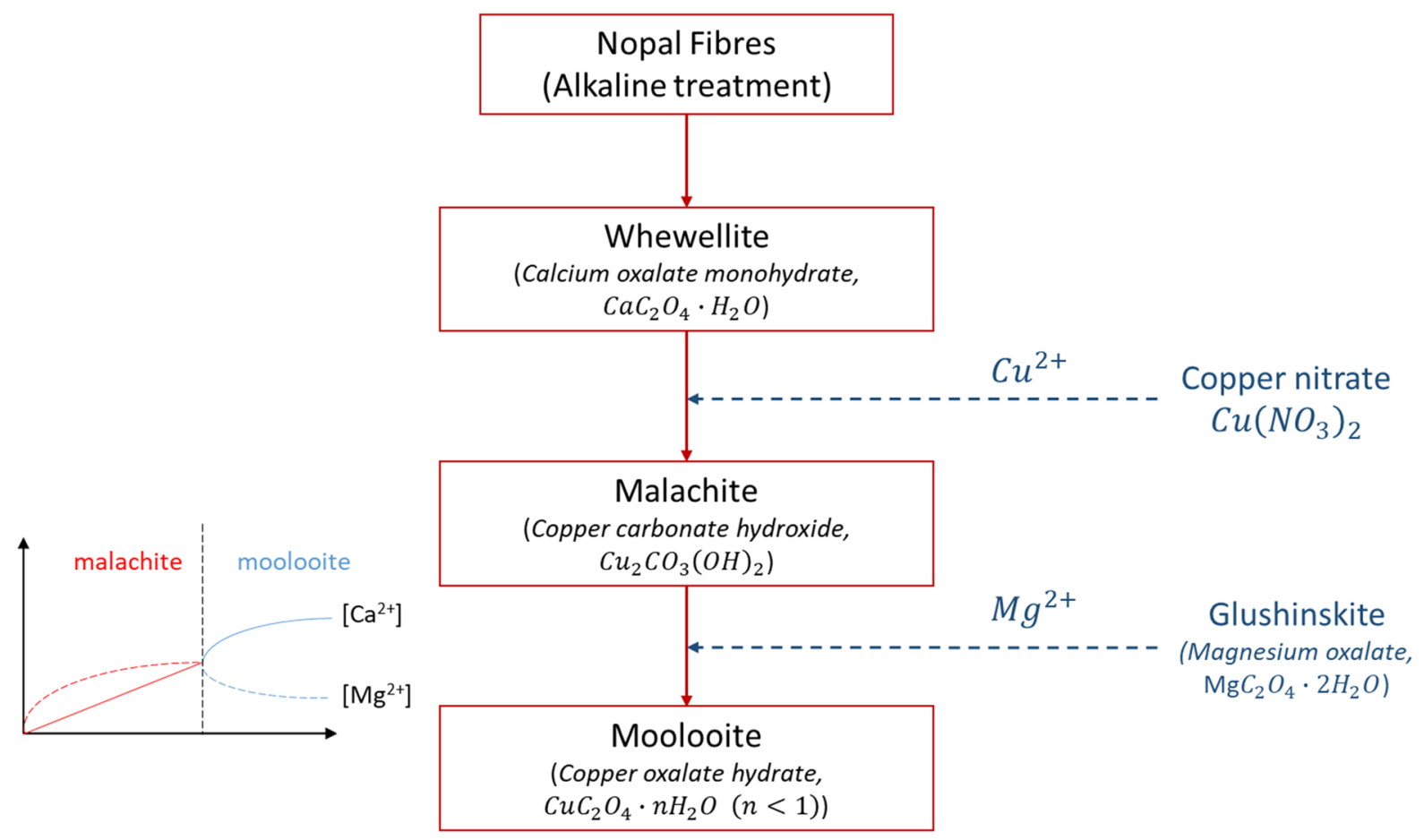

Fig. 13 Reactive crystallization mechanism of the transformation of malachite into moolooite

predominates. An important finding from this study is the specific role magnesium played in the transformation of malachite crystals into moolooite. As the new crystal formed, the system displayed a polymorphspecific evolution of $\mathrm{pH}$ and $\mathrm{Mg} / \mathrm{Ca}$ ratio. Finally, the reactive mechanism here described might contribute not only to the understanding of the biosorption mechanism of heavy metals on plant biomass but also elucidate the mechanism involved in the biodeterioration of artwork by microorganisms through oxalate formation and complement actual knowledge on the mechanism of kidney stone formation.

Acknowledgments The project is jointly funded by the British Council Institutional Links programme (Newton Fund) (Grant No. 264232317) and Consejo Nacional de Ciencia y Tecnología (CONACYT) through the Institutional LinksFONCICYT Program (Grant No. 276243).

Open Access This article is licensed under a Creative Commons Attribution 4.0 International License, which permits use, sharing, adaptation, distribution and reproduction in any medium or format, as long as you give appropriate credit to the original author(s) and the source, provide a link to the Creative Commons licence, and indicate if changes were made. The images or other third party material in this article are included in the article's Creative Commons licence, unless indicated otherwise in a credit line to the material. If material is not included in the article's Creative Commons licence and your intended use is not permitted by statutory regulation or exceeds the permitted use, you will need to obtain permission directly from the copyright holder. To view a copy of this licence, visit http://creativecommons.org/licenses/by/4.0/.

\section{References}

Abdul Khalil HPS, Davoudpour Y, Islam MN et al (2014) Production and modification of nanofibrillated cellulose using various mechanical processes: a review. Carbohydr Polym 99:649-665. https://doi.org/10.1016/j.carbpol. 2013.08.069

Atakan IH, Kaplan M, Seren G et al (2007) Serum, urinary and stone zinc, iron, magnesium and copper levels in idiopathic calcium oxalate stone patients. Int Urol Nephrol 39:351-356. https://doi.org/10.1007/s11255-006-9050-4

Barka N, Abdennouri M, El Makhfouk M, Qourzal S (2013) Biosorption characteristics of cadmium and lead onto ecofriendly dried cactus (Opuntia ficus indica) cladodes. J Environ Chem Eng 1:144-149. https://doi.org/10.1016/j. jece.2013.04.008

Barrera H, Ureña-Núñez F, Bilyeu B, Barrera-Díaz C (2006) Removal of chromium and toxic ions present in mine drainage by Ectodermis of Opuntia. J Hazard Mater 136:846-853. https://doi.org/10.1016/j.jhazmat.2006.01. 021 
Beltrán-Hernández RI, Vázquez-Rodríguez GA, Juárez-Santillán LF et al (2015) Cadmium removal from aqueous systems using opuntia albicarpa L. Scheinvar as Biosorbent. Biomed Res Int. https://doi.org/10.1155/2015/ 832571

Bernardo GRR, Rene RMJ (2009) Chromium (III) uptake by agro-waste biosorbents: chemical characterization, sorption-desorption studies, and mechanism. J Hazard Mater 170:845-854. https://doi.org/10.1016/j.jhazmat.2009.05. 046

Bilal M, Shah JA, Ashfaq T et al (2013) Waste biomass adsorbents for copper removal from industrial wastewater: a review. J Hazard Mater 263:322-333. https://doi.org/10. 1016/j.jhazmat.2013.07.071

Brinchi L, Cotana F, Fortunati E, Kenny JM (2013) Production of nanocrystalline cellulose from lignocellulosic biomass: technology and applications. Carbohydr Polym 94:154-169. https://doi.org/10.1016/j.carbpol.2013.01. 033

Castro K, Sarmiento A, Martínez-Arkarazo I et al (2008) Green copper pigments biodegradation in cultural heritage: from malachite to moolooite, thermodynamic modeling, X-ray fluorescence, and raman evidence. Anal Chem 80:4103-4110. https://doi.org/10.1021/ac800255w

Contreras-Padilla M, Rivera-Muñoz EM, Gutiérrez-Cortez E et al (2015) Characterization of crystalline structures in Opuntia ficus-indica. J Biol Phys 41:99-112. https://doi. org/10.1007/s10867-014-9368-6

Contreras-Padilla M, Rodríguez-García ME, Gutiérrez-Cortez E et al (2016) Physicochemical and rheological characterization of Opuntia ficus mucilage at three different maturity stages of cladode. Eur Polym J 78:226-234. https://doi.org/ 10.1016/j.eurpolymj.2016.03.024

Davey RJ (1976) The effect of impurity adsorption on the kinetics of crystal growth from solution. J Cryst Growth 34:109-119. https://doi.org/10.1016/00220248(76)90268-2

Demartin F, Campostrini I, Ferretti P, Rocchetti I (2018) Fiemmeite $\mathrm{Cu}_{2}\left(\mathrm{C}_{2} \mathrm{O}_{4}\right)(\mathrm{OH})_{2} \bullet 2 \mathrm{H}_{2} \mathrm{O}$, a new mineral from Val di Fiemme, Trentino, Italy. Minerals 8:1-10. https:// doi.org/10.3390/min8060248

Du Y, Lian F, Zhu L (2011) Biosorption of divalent Pb, Cd and $\mathrm{Zn}$ on aragonite and calcite mollusk shells. Environ Pollut 159:1763-1768. https://doi.org/10.1016/j.envpol.2011.04. 017

Ebadi A, Soltan Mohammadzadeh JS, Khudiev A (2009) What is the correct form of BET isotherm for modeling liquid phase adsorption? Adsorption. https://doi.org/10.1007/ s10450-009-9151-3

Escudero C, Fiol N, Villaescusa I, Bollinger JC (2017) Effect of chromium speciation on its sorption mechanism onto grape stalks entrapped into alginate beads. Arab J Chem 10:S1293-S1302. https://doi.org/10.1016/j.arabjc.2013. 03.011

Fernández-López JA, Angosto JM, Avilés MD (2014) Biosorption of hexavalent chromium from aqueous medium with opuntia biomass. Sci World J. https://doi.org/10. $1155 / 2014 / 670249$

Goldberg S (1993) Chemistry of the solid-water interface processes at the mineral-water and particle-water interface in natural systems
Khan SR, Atmani F, Glenton P et al (1996) Lipids and membranes in the organic matrix of urinary calcific crystals and stones. Calcif Tissue Int. https://doi.org/10.1007/ s002239900140

Kim DS, Park BY (2001) Effects on the removal of $\mathrm{Pb}^{2+}$ from aqueous solution by crab shell. J Chem Technol Biotechnol 76:1179-1184. https://doi.org/10.1002/jctb.505

Kitamura M (2009) Strategy for control of crystallization of polymorphs. CrystEngComm 11:949-964. https://doi.org/ 10.1039/b809332f

Kotrba P, Ruml T (2010) Surface display of metal fixation motifs of bacterial Pi-Type ATPases specifically promotes biosorption of $\mathrm{Pb}^{2+}$ by Saccharomyces cerevisiae. Appl Environ Microbiol 76:2615-2622. https://doi.org/10.1128/ AEM.01463-09

Kotrba P, Mackova M, Macek T (2011) Microbial biosorption of metals

Lee MY, Park JM, Yang JW (1997) Micro precipitation of lead on the surface of crab shell particles. Process Biochem 32:671-677. https://doi.org/10.1016/S00329592(97)00026-5

Leung WH, Nancollas GH (1978) Nitrilotri (methylenephosphonic acid) adsorption on barium sulfate crystals and its influence on crystal growth. J Cryst Growth 44:163-167. https://doi.org/10.1016/0022-0248(78)90190-2

Malainine ME, Dufresne A, Dupeyre D et al (2003) Structure and morphology of cladodes and spines of Opuntia ficusindica: cellulose extraction and characterisation. Carbohydr Polym 51:77-83. https://doi.org/10.1016/S01448617(02)00157-1

Mielniczek-Brzóska E, Gielzak-Koćwin K, Sangwal K (2000) Effect of $\mathrm{Cu}(\mathrm{II})$ ions on the growth of ammonium oxalate monohydrate crystals from aqueous solutions: growth kinetics, segregation coefficient and characterization of incorporation sites. J Cryst Growth 212:532-542. https:// doi.org/10.1016/S0022-0248(00)00326-2

Miretzky P, Muñoz C, Carrillo-Chávez A (2008) Experimental binding of lead to a low cost on biosorbent: nopal (Opuntia streptacantha). Bioresour Technol 99:1211-1217. https:// doi.org/10.1016/j.biortech.2007.02.045

Monje PV, Baran EJ (2005) Evidence of formation of glushinskite as a biomineral in a Cactaceae species. Phytochemistry 66:611-614. https://doi.org/10.1016/j.phytochem. 2004.12.025

Moon RJ, Martini A, Nairn J, et al (2011) Cellulose nanomaterials review: structure, properties and nanocomposites

Morse JW, Arvidson RS, Lüttge A (2007) Calcium carbonate formation and dissolution. Chem Rev 107:342-381. https://doi.org/10.1021/cr050358j

Myerson AS (2002) Handbook of industrial crystallization

Nharingo T, Moyo M (2016) Application of Opuntia ficusindica in bioremediation of wastewaters. A critical review. J Environ Manag 166:55-72. https://doi.org/10.1016/j. jenvman.2015.10.005

Prodromou M, Pashalidis I (2013) Copper(II) removal from aqueous solutions by adsorption on non-treated and chemically modified cactus fibres. Water Sci Technol 68:2497-2504. https://doi.org/10.2166/wst.2013.535

Rakotomalala R (2005) TANAGRA: a free software for research and academic purposes. In: Proceedings of EGC, pp 697-702 
Ramezani Kakroodi A, Panthapulakkal S, Sain M, Asiri A (2015) Cellulose nanofibers from the skin of beavertail cactus, Opuntia basilaris, as reinforcements for polyvinyl alcohol. J Appl Polym Sci. https://doi.org/10.1002/app. 42499

Robalds A, Naja GM, Klavins M (2016) Highlighting inconsistencies regarding metal biosorption. J Hazard Mater 304:553-556

Rosado T, Gil M, Mirão J et al (2013) Oxalate biofilm formation in mural paintings due to microorganisms: a comprehensive study. Int Biodeterior Biodegrad. https://doi.org/10. 1016/j.ibiod.2013.06.013

Rousseau RW, Tai CY, McCabe WL (1976) The influence of quinoline yellow on potassium alum growth rates. J Cryst Growth 32:73-76. https://doi.org/10.1016/00220248(76)90011-7

Ruthven DM (1984) Principles of adsorption and adsorption process

Ryall RL (2011) The possible roles of inhibitors, promoters, and macromolecules in the formation of calcium kidney stones. In: Urinary tract stone disease

Schneider IAH, Rubio J, Smith RW (2001) Biosorption of metals onto plant biomass: exchange adsorption or surface precipitation? Int J Miner Process 62:111-120. https://doi. org/10.1016/S0301-7516(00)00047-8

Selvaraju R, Raja A, Thiruppathi G (2013) Chemical composition and binary mixture of human urinary stones using FT-Raman spectroscopy method. Spectrochim Acta - Part A Mol Biomol Spectrosc. https://doi.org/10.1016/j.saa. 2013.05.029

Singh VK, Rai PK (2014) Kidney stone analysis techniques and the role of major and trace elements on their pathogenesis: a review. Biophys Rev 6:291-310. https://doi.org/10.1007/ s12551-014-0144-4

Stevens PF (2017) Angiosperm phylogeny website. In: Version 14, July 2017. http://www.mobot.org/MOBOT/research/ APweb/welcome.html

Velazquez Jimenez LH, Rangel Mendez JR (2014) Adsorption of inorganic priority pollutants in water by tailored lignocellulosic and carbonaceous adsorbents

Vijayaraghavan K, Joshi UM, Balasubramanian R (2010) Removal of metal ions from storm-water runoff by lowcost sorbents: batch and column studies. 1113-1119. https://doi.org/10.1061/ASCEEE.1943-7870.0000238

Vijayaraghavan K, Winnie HYN, Balasubramanian R (2011) Biosorption characteristics of crab shell particles for the removal of manganese(II) and zinc(II) from aqueous solutions. Desalination 266:195-200. https://doi.org/10. 1016/j.desal.2010.08.026

Wahab MA, Boubakri H, Jellali S, Jedidi N (2012) Characterization of ammonium retention processes onto Cactus leaves fibers using FTIR, EDX and SEM analysis. J Hazard Mater 241-242:101-109. https://doi.org/10.1016/j. jhazmat.2012.09.018

Xu M, Higgins SR (2011) Effects of magnesium ions on nearequilibrium calcite dissolution: step kinetics and morphology. Geochim Cosmochim Acta 75:719-733. https:// doi.org/10.1016/j.gca.2010.10.018

Publisher's Note Springer Nature remains neutral with regard to jurisdictional claims in published maps and institutional affiliations. 